DOI: http://dx.doi.org/10.18203/2320-1770.ijrcog20174440

Original Research Article

\title{
Reproductive surgery in infertility
}

\author{
Shilpi S. Sud ${ }^{1}$, Suneet K. Sud ${ }^{2}$, Jayshree J. Upadhye ${ }^{3 *}$
}

\begin{abstract}
${ }^{1}$ Department of Obstetrics and Gynecology, ${ }^{2}$ Department of Surgery, Safal hospital, Nagpur, Maharashtra, India ${ }^{3}$ Department of Gynecology and Obstetrics, Upadhye Children hospital, Nagpur, Maharashtra, India
\end{abstract}

Received: 03 August 2017

Accepted: 01 September 2017

\section{*Correspondence:}

Dr. Jayshree J. Upadhye,

E-mail: jayshreeupadhye@gmail.com

Copyright: (C) the author(s), publisher and licensee Medip Academy. This is an open-access article distributed under the terms of the Creative Commons Attribution Non-Commercial License, which permits unrestricted non-commercial use, distribution, and reproduction in any medium, provided the original work is properly cited.

\section{ABSTRACT}

Background: With recent improvements in the assisted reproductive technology (ART), there has been a growing tendency that bypasses diagnostic laparohysteroscopy and proceeds directly to ART. Therefore, the value of diagnostic laparohysteroscopy in current fertility practice is under debate. In the present study, we evaluated the usefulness of diagnostic laparoscopy and hysteroscopy for patients with infertility.

Methods: This retrospective study was conducted at Safal Hospital, Nagpur from January 2017 to July 2017. 80 patients were selected for this study who had undergone diagnostic laparohysteroscopy for infertility.

Results: In present study, out of 80 patients studied, $66.25 \%$ patients had normal hysteroscopy findings, in $10 \%$ of patients, tubal cannulation was done for cornual block, in $6.25 \%$ of patients, resection of uterine septum was done, adhesiolysis for asherman's syndrome was done in 5\% of patients, endometrial polyp was removed in 5\% of patients, $2.5 \%$ patients had resection of submucous fibroid. In $5 \%$ patients, cervical dilatation for fibrosis was done in $5 \%$ of patients. $68.75 \%$ had normal laparoscopy findings, in $8.75 \%$ of patients, ovarian drilling for PCOS was done, adhesiolysis for peritubal adhesions was done in $6.25 \%$ patients, fulguration of endometriosis was done in $6.25 \%$ patients, salpingectomy for hydrosalpinx was done in $5 \%$ patients, aspiration of ovarian cyst was done in $2.5 \%$ patients.

Conclusions: Diagnostic hysterolaparoscopy is an effective diagnostic and therapeutic modality for certain significant and correctable abnormalities in pelvis, tubes and uterus which are missed by other imaging modalities.

Keywords: Hysteroscopy, Infertility, Laparoscopy

\section{INTRODUCTION}

Tuboperitoneal pathology is responsible for $40-50 \%$ cases of infertility. Hysterosalpingography (HSG) and laparoscopy are the two classic methods available for evaluation of tubal pathology and are complementary to each other. Though pelvic sonography and HSG are good enough to exclude gross intrauterine pathology, but subtle changes in the form of small polyps, adhesions and seedling fibroid are better picked up on magnification with hysteroscopy. Combined hysterolaparoscopy may obviate need for HSG, as complete evaluation and treatment is possible in the same sitting. ${ }^{1}$

The routine use of diagnostic laparoscopy for the evaluation of all cases of female infertility is currently under debate. According to data published in retrospective non-controlled studies, diagnostic laparoscopy after several failed cycles of ovulation induction enables the detection of a significant proportion of pelvic pathology amenable to treatment. ${ }^{2}$ 
The role of laparoscopy before the start of treatment with intrauterine insemination is controversial, according to one RCT. ${ }^{2}$ Some specific clinical settings, solid evidence is available to recommend the use of diagnostic laparoscopy in current fertility practice. ${ }^{2}$

There is no evidence for an increase in pregnancy rates in assisted reproductive technology cycles following surgical treatment of pelvic adhesions or endometriosis with laparoscopy. If the patient has bilateral visible hydrosalpinges, laparoscopy may be an option for evaluation of the tubes and treatment with salpingectomy in order to enhance the chance of pregnancy before commencing an assisted reproductive technology cycle. Laparoscopic ovarian drilling before assisted reproductive technology may be considered a therapeutic option in polycystic ovary disease patients who previously had severe ovarian hyperstimulation syndrome. Finally, laparoscopy may be useful in replacing the transposed ovaries to their original sites in the pelvic cavity in previously treated cancer patients so that monitoring of the controlled ovarian hyperstimulation and the oocyte aspiration would be much easier during the assisted reproductive technology cycles. $^{3}$

The challenge for the reproductive specialist is to know and utilize reproductive surgery appropriately and effectively in the management of unexplained infertility, endometriosis, myomas, hydrosalpinges, proximal tubal occlusion, adhesions, ectopic pregnancy, tubal reversal, laparoscopic ovarian drilling for polycystic ovarian disease, as an adjunct to assisted reproductive technologies and in other clinical reproductive conditions. $^{4}$

Reproductive surgery is more than a competing discipline; it is complementary to the techniques of invitro fertilisation. As a complementary discipline, reproductive surgery covers the field of tubal and ovarian pathology and correction of uterine alterations. ${ }^{5}$

Reproductive surgery could be divided into surgery as a primary treatment for infertility, surgery to enhance invitro fertilisation outcome, and surgery for fertility preservation. A shift has occurred away from surgery as a primary treatment of infertility to surgery playing a crucial part in enhancing in-vitro fertilisation outcome and for fertility preservation. A normal uterine cavity is a prerequisite for implantation, and hysteroscopic correction of intrauterine pathology, including polypectomy, myomectomy and metroplasty, increases the chances of having a successful pregnancy. Management of hydrosalpinx before in-vitro fertilisation treatment by laparoscopic salpingectomy or proximal tubal occlusion increases the in-vitro fertilisation delivery rate. Finally, surgery plays an important role in preservation of fertility. This includes laparoscopic ovarian transposition, ovarian tissue removal for cryopreservation and ovarian transplantation. ${ }^{6}$
Uterine abnormalities, including congenital pathologies, polyps, submucous leiomyomata, intrauterine adhesions, and chronic endometritis, have been reported in 21 to $47 \%$ of patients undergoing in vitro fertilization cycles. The position of hysteroscopy in current fertility practice is under debate. Although there are many randomized controlled trials on technical feasibility and patient compliance demonstrating that the procedure is well tolerated and effective in the treatment of intrauterine pathologies, there is no consensus on the effectiveness of hysteroscopic surgery in improving the prognosis of subfertile women. However, in patients with at least two failed cycles of assisted reproductive technology, diagnostic hysteroscopy and, if necessary, operative hysteroscopy is mandatory to improve reproductive outcome. Office hysteroscopy is a powerful tool for the diagnosis and treatment of intrauterine benign pathologies. It is a simple, safe, reproducible, effective, quick, well-tolerated, and low-cost surgical procedure, with no need for an operating room. ${ }^{7}$

The randomized trials do not clearly demonstrate that surgical correction of all intrauterine abnormalities improves IVF outcome. However, published observational studies suggest a benefit for resection of submucosal leiomyomas, adhesions, and endometrial polyps in increasing pregnancy rates. ${ }^{8}$

Expectant management of small and asymptomatic polyps is reasonable in many cases. However, surgical resection of endometrial polyps is recommended in infertile patients prior to treatment in order to increase natural conception or assisted reproductive pregnancy rates. There is mixed evidence regarding the resection of newly diagnosed endometrial polyps during ovarian stimulation to improve the outcomes of fresh in vitro fertilization cycles. Hysteroscopy polypectomy remains the gold standard for surgical treatment. ${ }^{9}$

The introduction of small diameter hysteroscopes and resectoscopes-often no larger than a SIS catheter-now allows most women with abnormal ultrasound findings to undergo a single-stage "see-and-treat" hysteroscopy for the management of endometrial polyps. In order to provide optimal management of endometrial polyps, however, a variety of known and unknown factors must be considered prior to "see-and-treat" hysteroscopy. For a woman wishing to preserve or enhance her fertility, hysteroscopic polypectomy-with care to avoid collateral endometrial damage-remains the standard of care. ${ }^{9}$

In women without a previous history suggestive of tubal disease and who have a normal HSG, it was demonstrated that the probability of clinically relevant tubal disease or endometriosis is very low and that laparoscopy does not seem justified or cost effective. In the minority of these cases, laparoscopy might reveal minimal or mild endometriosis or peritubal adhesions. In these cases, either surgery or medical treatment has not been proven to improve fecundity. ${ }^{10}$ 


\section{METHODS}

This study was a retrospective analysis carried out at infertility clinic on 80 women who have undergone laparohysteroscopy for infertility. A total of 80 patients who had undergone laparohysteroscopy for infertility were studied retrospectively. Details of name, age, primary or secondary infertility were noted.

As part of the surgical evaluation, the following were examined-

- Evaluation of the tubes and ovaries.

- Exclusion of endometriosis,

- Identification of adhesions

- Inspection of the uterus and the exclusion of fibroids

- Inspection of the appendix, intestine, gall bladder, liver, and upper abdominal cavity

- Examination of uterine cavity for polyp, submucous fibroid,

- Identification of Asherman syndrome

Wherever possible, corrective surgery was done as follows

By hysteroscopy

- Resection of submucous fibroids

- Polypectomy for endometrial polyp

- Resection for uterine septum

- Adhesiolysis for asherman's syndrome

By laparoscopy

- Fulguration of endometriosis

- Drilling of PCOS

- Removal of tubo-ovarian mass /ovarian cyst

- Adhesiolysis of peritubal adhesions

- Salpingectomy for hydrosalpinx

Data was collected in excel sheet and studied.

\section{RESULTS}

Maximum patients i.e. 34 (42.5\%) patients were between 26-30 years, $20(25 \%)$ patients were between $31-35$ years, $17(21.25 \%)$ patients were between $36-40$ years, 6 (7.5\%) patients were between 21-25 years while only 3 (3.75\%) of patients were above 40 years of age.

Table 1: Age group.

\begin{tabular}{|lll|}
\hline A ge group & No. of patients & $\%$ \\
\hline 21-25 years & 6 & 7.5 \\
\hline 26-30 years & 34 & 42.5 \\
\hline 31-35 years & 20 & 25 \\
\hline 36-40 years & 17 & 21.25 \\
\hline$>40$ years & 3 & 3.75 \\
\hline
\end{tabular}

Table 2: Type of infertility.

\begin{tabular}{|lll|}
\hline Type of infertility & No. of patients & $\%$ \\
\hline Primary & 69 & 86.35 \\
\hline Secondary & 11 & 13.75 \\
\hline
\end{tabular}

In present study, $69(86.35 \%)$ of patients had primary infertility while $11(13.75 \%)$ of patients had secondary infertility.

Table 3: Hysteroscopic procedures done.

\begin{tabular}{|lll|}
\hline Hysteroscopic procedures & No. of patients $\%$ \\
\hline Normal findings & 53 & 66.25 \\
\hline Tubal cannulation & 8 & 10 \\
\hline Resection of septum & 5 & 6.25 \\
\hline $\begin{array}{l}\text { Adhesiolysis for Asherman } \\
\text { syndrome }\end{array}$ & 4 & 5 \\
\hline Endometrial Polyp removal & 4 & 5 \\
\hline $\begin{array}{l}\text { Resection of submucous } \\
\text { fibroid }\end{array}$ & 2 & 2.5 \\
\hline $\begin{array}{l}\text { Cervical dilatation for } \\
\text { fibrosis }\end{array}$ & 4 & 5 \\
\hline
\end{tabular}

In present study, $66.25 \%$ patients had normal hysteroscopy findings, in $10 \%$ of patients, tubal cannulation was done for corneal block, in $6.25 \%$ of patients, resection of uterine septum was done, ahesiolysis for asherman's syndrome was done in $5 \%$ of patients, endometrial polyp was removed in 5\% of patients, $2.5 \%$ patients had resection of submucous fibroid. In $5 \%$ patients, cervical dilatation was for fibrosis was done in $5 \%$ of patients.

Table 4: Laparoscopic procedures done.

\begin{tabular}{|c|c|c|}
\hline Laparoscopic procedures & $\begin{array}{l}\text { No. of } \\
\text { patients }\end{array}$ & $\%$ \\
\hline Normal findings & 55 & 68.75 \\
\hline PCOS drilling & 7 & 8.75 \\
\hline $\begin{array}{l}\text { Adhesiolysis for peritubal } \\
\text { adhesions }\end{array}$ & 5 & 6.25 \\
\hline Fulguration of endometriosis & 5 & 6.25 \\
\hline Salpingectomy for hydrosalpinx & 4 & 5 \\
\hline Aspiration of ovarian cyst & 2 & 2.5 \\
\hline Removal of TO mass & 2 & 2.5 \\
\hline
\end{tabular}

In present study, $68.75 \%$ had normal laparoscopy findings, in $8.75 \%$ of patients, ovarian drilling for PCOS was done, adhesiolysis for peritubal adhesions was done in $6.25 \%$ patients, fulguration of endometriosis was done in $6.25 \%$ patients, salpingectomy for hydrosalpinx was done in $5 \%$ patients, aspiration of ovarian cyst was done in $2.5 \%$ patients while removal of $\mathrm{TO}$ mass was done in $2.5 \%$ patients.

In present study, hysteroscopic procedures were done in $27(33.75 \%)$ patients while laparoscopic procedures were done in $25(31.25 \%)$. 
Table 5: Total procedures done.

\begin{tabular}{|lll|}
\hline Total procedures & No. of patients & $\%$ \\
\hline Hysteroscopy procedures & 27 & 33.75 \\
\hline Laparoscopy procedures & 25 & 31.25 \\
\hline
\end{tabular}

\section{DISCUSSION}

In present study, out of 80 patients studied, maximum patients i.e. $34(42.5 \%)$ patients were between 26-30 years, $20(25 \%)$ patients were between 31-35 years, 17 $(21.25 \%)$ patients were between $36-40$ years, $6(7.5 \%)$ patients were between $21-25$ years while only $3(3.75 \%)$ of patients were above 40 years of age.

In present study, $66.25 \%$ patients had normal hysteroscopy findings, in $10 \%$ of patients, tubal cannulation was done for corneal block, in $6.25 \%$ of patients, resection of uterine septum was done, adhesiolysis for asherman's syndrome was done in $5 \%$ of patients, endometrial polyp was removed in 5\% of patients, $2.5 \%$ patients had resection of submucous fibroid. In 5\% patients, cervical dilatation for fibrosis was done in $5 \%$ of patients.

Vaid $\mathrm{K}$ et al found that in comparing HSG and Hysteroscopy, uterine findings matched in $66.3 \%$ patients. HSG failed to detect uterine pathology in $32.12 \%$ patients $(62 / 193)$ with a sensitivity of $21.3 \%$ and specificity of $97.45 \%$. $93 \%$ of intrauterine adhesions/polyps were missed on HSG. Hysteroscopic intervention was required in $23.83 \%$ cases, adhesiolysis being the commonest. On comparing tubal patency on HSG and laparoscopy, the sensitivity of HSG in detecting bilateral tubal block was $80.6 \%$ and specificity of $81.5 \%$. With regard to unilateral tubal block, sensitivity was $34.6 \%$ and specificity $89.8 \%$. The agreement between the two was $74 \%$. Pathology such as adhesions, fimbrial agglutination and endometriosis were dealt surgically in $65.8 \%$ patients. As per HSG, 112/193 women had both tubes patent and 177 revealed normal uterine cavity. When these 112 women $(58.03 \%)$ with normal HSG report were further subjected to hysterolaparoscopy, only $35 / 193(18.13 \%)$ of them actually had normal tubes and uterus; rest 77 women $(39.89 \%)$ were benefited by one step procedure of hysterolaparoscopic evaluation and intervention and further treatment done. ${ }^{1}$

In present study, $68.75 \%$ had normal laparoscopy findings, in $8.75 \%$ of patients, ovarian drilling for PCOS was done, adhesiolysis for peritubal adhesions was done in $6.25 \%$ patients, fulguration of endometriosis was done in $6.25 \%$ patients, salpingectomy for hydrosalpinx was done in $5 \%$ patients, aspiration of ovarian cyst was done in $2.5 \%$ patients while removal of TO mass was done in $2.5 \%$ patients.

Tsuji I found that in $46(80.7 \%)$ of these patients, diagnostic laparoscopy revealed pathologic abnor malities. Specifically, endometriosis and peritubal and/or perifimbrial adhesions were found in $36(63.2 \%)$ and 5 $(8.8 \%)$ of the patients, respectively. In 8 patients $(14.0 \%)$, the management plan was switched to ART because of severe tubal diseases. Among the 57 patients, 29 pregnancies $(50.9 \%)$ were achieved, including 6 ARTmediated pregnancies. ${ }^{11}$

Jozwiak A et al found that in 17 out of $53(32 \%)$ patients who underwent the surgical procedure a clinical pregnancy was diagnosed. 11 out of 53 (20.75\%) women became pregnant spontaneously, 6 out of $53(11.32 \%)$ patients became pregnant as a result of assisted reproductive technology (ART) (5 IVF and 1 IUI). The average time from the date of surgical procedure to spontaneous pregnancy amounted to 6 months. ${ }^{12}$

In present study, $69(86.35 \%)$ of patients had primary infertility while $11(13.75 \%)$ of patients had secondary infertility.

In present study, hysteroscopic procedures were done in $27(33.75 \%)$ patients while laparoscopic procedures were done in $25(31.25 \%)$.

Nayak PK et al found that out of 300 cases, 206 (69\%) patients had primary infertility. While laparoscopy detected abnormalities in $34 \%$ of the cases, significant hysteroscopy findings were noted in $18 \%$ of cases. Together, diagnostic hysterolaparoscopy detected abnormalities in $26 \%$ of the infertile patients in both groups. While the most common laparoscopic abnormality was endometriosis (14\%) and adnexal adhesion (12\%) in primary and secondary infertile patients, respectively, hysteroscopy found intrauterine septum as the most common abnormality in both groups. ${ }^{13}$

Kabadi YM found that out of 94 cases, $53.1 \%$ patients had primary, $17.1 \%$ patients had secondary infertility, and $29.8 \%$ came for tubal recanalization. As a whole pelvic pathology was confirmed in $51.7 \%$ and intrauterine pathology in $18.1 \%$ patients by hysterolaparoscopy. The most common laparoscopic abnormality detected was ovarian pathology (20.8\%), followed by pelvic inflammatory disease $(17.5 \%)$. Tubal block comprised $7.7 \%$ whereas distorted uterus by fibroid in $6.6 \%$ and pelvic endometriosis in $5.4 \%$. In hysteroscopy, the incidence of uterine anomaly was 13 $(13.8 \%)$. Septate uterus is the most common with a mean incidence of approximately $7(53.8 \%){ }^{14}$

Zhang E. et al reported that out of 132 infertile patients included, $71(53.8 \%)$ women had primary infertility and the rest $61(46.2 \%)$ had secondary infertility. Laparoscopic abnormalites were more common than hysteroscopy abnormalites both in primary infertility group and secondary infertility group. Pelvic inflammatory disease $(59.09 \%)$ and endometriosis $(29.55 \%)$ were the most common abnormalities in two groups. The most common intrauterine pathology was 
uterine polyps and the most common uterine malformation was uterine septum in two groups. Out of 12 patients having malformation uterus, only one was double uterus and double cervical with double vagina. There was no major surgical or anesthetic complication in any of our patients, other than mild abdominal pain. ${ }^{15}$

Nayak PK et al reported that out of 300 cases, $206(69 \%)$ patients had primary infertility. While laparoscopy detected abnormalities in $34 \%$ of the cases, significant hysteroscopy findings were noted in $18 \%$ of cases. Together, diagnostic hysterolaparoscopy detected abnormalities in $26 \%$ of the infertile patients in both groups. While the most common laparoscopic abnormality was endometriosis (14\%) and adnexal adhesion (12\%) in primary and secondary infertile patients, respectively, hysteroscopy found intrauterine septum as the most common abnormality in both groups.

Bosteels $\mathrm{J}$ et al found that hysteroscopic removal of endometrial polyps with a mean diameter of $16 \mathrm{~mm}$ detected by ultrasound doubles the pregnancy rate when compared with diagnostic hysteroscopy and polyp biopsy in patients undergoing intrauterine insemination, starting 3 months after the surgical intervention [relative risk $(\mathrm{RR})=2.3 ; 95 \%$ confidence interval $(\mathrm{CI})$ : 1.6-3.2]. In patients with one fibroid structure smaller than $4 \mathrm{~cm}$, there was a marginally significant benefit from myomectomy when compared with expectant management $(\mathrm{RR}=1.9 ; 95 \% \mathrm{CI}: 1.0-3.7)$. Hysteroscopic metroplasty for septate uterus resulted in fewer pregnancies in patients with subfertility when compared with those with recurrent pregnancy loss $(\mathrm{RR}=0.7 ; 95 \%$ CI: 0.5-0.9). Randomized controlled studies on hysteroscopic treatment of intrauterine adhesions are lacking. Hysteroscopy in the cycle preceding a subsequent IVF attempt nearly doubles the pregnancy rate in patients with at least two failed IVF attempts compared with starting IVF immediately $(\mathrm{RR}=1.7 ; 95 \%$ CI: $1.5-2.0) .{ }^{16}$

Di SSA reported that results on pregnancy rate were confirmed in the subgroup analysis of five studies including only women with one or more implantation failures (RR 1.41, 95\% CI 1.14-1.75) and three studies where hysteroscopy was performed before the first IVF/ICSI attempt (RR 1.55, 95\% CI 1.26-1.91). Comparing operative hysteroscopy for intrauterine abnormalities in infertile women with already diagnosed polyps or fibroids, there was low-quality evidence that operative hysteroscopy increases pregnancy rate (RR $2.13,95 \%$ CI 1.56-2.92). None of the studies comparing operative versus diagnostic hysteroscopy assessed LBR. ${ }^{17}$

Donnez $\mathbf{J}$ et al found that hysterosalpingography and laparoscopy were performed in 500 infertile women. Results obtained by both techniques were compared. Taking into consideration only the tubal patency, the present study shows an agreement in $90 \%$ of cases. In total of 980 fallopian tubes examined, fimbrial conglutination was suspected in 79 tubes (8\%) and diagnosed by laparoscopy in 154 tubes $(15.7 \%)$. Peritubal adhesions with tubal patency are a frequent pathology $(23.8 \%)$ and hysterosalpingography alone permits the diagnosis in only $68.8 \%$ of the cases confirmed by laparoscopy. Other additional findings by laparoscopy are frequent: endometriosis was found in 124 women. Isolated periovarian adhesions were disclosed in 48 women. The high incidence of unsuspected pathology is an additional support in favor of laparoscopy in each case of infertility. ${ }^{18}$

Fatnassi R reported that the mean age was 32.3 years; the mean duration of infertility was 70.47 months. Laparoscopy revealed pelvic abnormalities in $45 \%$ of cases, dominated by disease tubo-adhesions (23\%), endometriosis was found in $6 \%$ of cases. These anomalies are considered major in $23 \%$ of cases and minor in $22 \%$ of cases. Conducting a surgical procedure in the same operating time (adhesiolysis, tubal plastic surgery, electrocoagulation of endometriosis implants) could improve the prognosis of fertility. Only 20 patients were followed among the 45 with pelvic abnormalities, seven pregnancies have been completed (35\% of cases). ${ }^{19}$

\section{CONCLUSION}

For fertility patients with a suspected diagnosis of endometriosis, fibroids, or polyps, or for those with a history of pelvic infection and also not responding to initial treatment, laparoscopy and hysteroscopy can be used simultaneously to ascertain the state of the uterine cavity

We conclude that diagnostic laparohysteroscopy is beneficial of infertility patients. Indeed, we are able to detect the cause(s) of infertility in the pelvic cavity and to design a suitable management plan, which could lead to pregnancy. Therefore, because of the potential diagnostic and therapeutic benefits, patients with unexplained infertility should undergo diagnostic laparohysteroscopy prior to ART.

Funding: No funding sources

Conflict of interest: None declared

Ethical approval: The study was approved by the Institutional Ethics Committee

\section{REFERENCES}

1. Vaid K, Mehra S, Verma M, Jain S, Sharma A, Bhaskaran S. Pan endoscopic approach hysterolaparoscopy as an initial procedure in selected infertile women. J Clin Diagn Res. 2014;8(2):95-8.

2. Bosteels J, Van Herendael B, Weyers S, D'Hooghe $\mathrm{T}$. The position of diagnostic laparoscopy in current fertility practice. Hum Reprod Update. 2007;13(5):477-85. 
3. Erel CT, Senturk LM. Is laparoscopy necessary before assisted reproductive technology? Curr Opin Obstet Gynecol. 2005;17(3):243-8.

4. Adamson GD. The modern role of reproductive surgery. Clin Obstet Gynecol. 2011;54(4):710-9.

5. Gordts S. New developments in reproductive surgery. Best Pract Res Clin Obstet Gynecol. 2013;27(3):431-40.

6. Tulandi T, Akkour K. Role of reproductive surgery in the era of assisted reproductive technology, Best Pract Res Clin Obstet Gynecol. 2012;26(6):747-55.

7. Bettocchi S, Achilarre MT, Ceci O, Luigi S, Fertility-enhancing hysteroscopic surgery. Semin Reprod Med. 2011;29(2):75-82.

8. Carneiro MM. What is the role of hysteroscopic surgery in the management of female infertility? A review of literature. Surg Res Pract. 2014;2014:105412.

9. Wortman M. See-and-Treat hysteroscopy in the management of endometrial Polyps. Surg Technol Int. 2016;28:177-84.

10. Fatum M, Laufer N, Simon A. Investigation of the infertile couple: should diagnostic laparoscopy be performed after normal hysterosalpingography in treating infertility suspected to be of unknown origin?, Hum Reprod. 2002;17(1):1-3

11. Tsuji I, Ami K, Miyazaki A, Hujinami N, Hoshiai H. Benefit of diagnostic laparoscopy for patients with unexplained infertility and normal hysterosalpingography findings. Tohoku J Exp Med. 2009;219(1):39-42.

12. Słabuszewska-Jóźwiak A, Ciebiera M, Baran A, Jakiel G. Effectiveness of laparoscopic surgeries in treating infertility related to endometriosis, Ann Agric Environ Med. 2015;22(2):329-31.

13. Nayak PK, Mahapatra PC, Mallick JJ, Swain S, Mitra S, Sahoo J. Role of diagnostic hystero- laparoscopy in the evaluation of infertility: A retrospective study of 300 patients, J Hum Reprod Sci. 2013;6(1):32-34.

14. Kabadi YM, Harsha B. Hysterolaparoscopy in the evaluation and management of female infertility. J Obstet Gynecol India. 2016;66(Suppl 1):478-81

15. Zhang E, Zhang Y, Fang L, Li Q, Gu J. Combined hysterolaparoscopy for the diagnosis of female infertility: a retrospective study of 132 patients in china. Mater Sociomed. 2014;26(3):156-7.

16. Bosteels J, Weyers S, Puttemans P, Panayotidis C, Van Herendael B, Gomel V at al. The effectiveness of hysteroscopy in improving pregnancy rates in subfertile women without other gynaecological symptoms: a systematic review. Hum Reprod Update. 2010;16(1):1-11.

17. Di Spiezio Sardo A, Di Carlo C, Minozzi S, Spinelli M, Pistotti V, Alviggi C et al. Efficacy of hysteroscopy in improving reproductive outcomes of infertile couples: a systematic review and metaanalysis. Hum Reprod Update. 2016;22(4):479-96.

18. Donnez J, Langerock S, Lecart C, Thomas K. Incidence of pathological factors not revealed by hysterosalpingography but disclosed by laparoscopy in 500 infertile women. Eur J Obstet Gynecol Reprod Biol. 1982;13(6):369-75.

19. Fatnassi R, Kaabia O, Laadhari S, Briki R, Dimassi $\mathrm{Z}$, Bibi $\mathrm{M}$ at al. Interest of laparoscopy in infertile couple with normal hysterosalpingography. Gynecol Obstet Fertil. 2014;42(1):20-6.

Cite this article as: Sud SS, Sud SK, Upadhye JJ. Reproductive surgery in infertility. Int J Reprod Contracept Obstet Gynecol 2017;6:4549-54. 